\title{
Drift reducing potential of low drift nozzles with the use of spray-hoods
}

\author{
R.L. Roten ${ }^{1}$, J.C. Ferguson ${ }^{2}$ and A.J. Hewitt ${ }^{3}$ \\ ${ }^{1}$ Lincoln Agritech Ltd., PO Box 69133, Lincoln, Christchurch 7640, New Zealand \\ ${ }^{2}$ Lincoln University, PO Box 7647, Lincoln, Christchurch 7647, New Zealand \\ ${ }^{3}$ The University of Queensland, Gatton QLD 4343, Australia \\ Corresponding author: rory.roten@lincolnagritech.co.nz
}

\begin{abstract}
A field study was conducted in November 2013 to assess the drift reduction potential of a three headed spray-hood unit with either DG95-02 or DG95-015 low-drift nozzles used with the hoods either on or off (DG nozzles calibrated at 0.6 litres $/ \mathrm{min}$ ). A standard treatment of 110-03 nozzles calibrated at 1.25 litres/min without hoods was the control. One tank mix of $0.4 \mathrm{~g} /$ litre PTSA (1,3,6,8-pyrenetetrasulfonic acid tetrasodium salt) fluorescent dye was used for all treatments. Petri dishes and aluminium plate collectors were placed at $0.25,0.5,1,2,5,10,25,50$ and $100 \mathrm{~m}$ downwind in three lines spaced at $10 \mathrm{~m}$. Collectors were placed in plastic bags under cool, dark storage until analysis. Results showed that total drift was reduced up to $99 \%$, compared to the control, when the spray hoods where used.
\end{abstract}

Keywords spray hoods, drift, PTSA.

\section{INTRODUCTION}

A drift reduction technology (DRT) is any type of addition to a standard spray application aimed at reducing spray drift. DRTs can include nozzles, directed solution placement (i.e. droplegs, wicks, hoods, etc) and/or droplet enhancers (airassistance, atomizers and electrostatics). Sprayhoods directly spray to a specific location and reduce spray-plume exposure to environmental effects (predominately wind) that contribute to spray drift. Hoods are common for inter-row weed control, but have not been widely used since glyphosate-resistant crops have been introduced throughout the world, particularly the United States (Dill et al. 2008).

Various spray-hoods have been developed and tested for their effects on deposition and drift using an assortment of technologies, such as sensor controlled application and multi-foil designs (Hanks \& Beck 1998; Sidahmed et al. 2004). Some hoods also allow a direct banded application of one solution while simultaneously broadcast spraying another solution thereby saving time, operating costs and the overall quantity of pesticide (Hanks \& Beck 1998; Carballido et al. 2013; Clayton 2014). With greater adoption of GPS and other guidance systems, large sprayers equipped with hoods will be far easier to use, and the risk of crop injury will be reduced.

Specialised low drift nozzles have also become widely available and are a less expensive way to reduce drift. The primary objective of this study was to combine a spray-hood technology with low drift nozzles and to assess their functionality 
as DRTs. A secondary objective was to examine aluminium plates and Petri dishes as collectors for PTSA (1,3,6,8-pyrenetetrasulfonic acid tetrasodium salt), a new dye in the drift industry.

\section{MATERIALS AND METHODS}

The study was conducted 11 and 12 November 2013 at the Johnstone Memorial Laboratory and Research Farm Facility in Springston, Canterbury (433' $\left.47.10^{\prime \prime} S 172^{\circ} 21^{\prime} 02.50^{\prime \prime} \mathrm{E}\right)$. The site was a recently grazed pasture (vegetation $\leq 10 \mathrm{~cm}$ tall) and all hedges were $\geq 450 \mathrm{~m}$ away. A V-style ultrasonic anemometer (Applied Technologies, Inc, Longmont, CO, USA) was used to measure wind speed and direction. Humidity and temperature were recorded every minute using a shielded Hummiter ${ }^{\circledR}$ 50Y weather station (Vaisala, Vantaa, Finland). Average temperature, humidity and wind speed shown in Table 1. Wind was also visually monitored to stay within the $30^{\circ}$ wind-angle allowance specified in an International Standard (ISO-22866: Methods for field measurement of spray drift).

The field study was consistent with the International Standard where the path of spraying was twice the sampling distance. Therefore, a $200 \mathrm{~m}$ driving path was created in an east to west fashion due to the prevailing southerly wind. Collectors were placed at $0.25,0.5,1,2,5$, $10,25,50$ and $100 \mathrm{~m}$ downwind in three separate lines, spaced at $10 \mathrm{~m}$. Collectors consisted of $150 \mathrm{~mm}$ Petri dishes and $130 \times 130 \mathrm{~mm}$ aluminium plates, which were produced inhouse to provide approximately the same surface area as the Petri dishes.

The application used a small scale, three-hood spray system with Varidome hoods and frame (Figure 1), and a $12 \mathrm{~V}$ high flow pump operating between 162 and $300 \mathrm{kPa}$. Each hood apparatus was mounted on the support rail with $500 \mathrm{~mm}$ spacing between units. Hoods were oriented at an angle to allow a $300 \mathrm{~mm}$ band application and set at $25 \mathrm{~mm}$ off of the ground. The five treatments included Drift Guard (DG; low drift) 95-02 nozzles with and without hoods; DG95-015 nozzles with and without hoods; and an ISO standard treatment of 110-03 with no hood. DG nozzles were calibrated at 0.6 litres/min and the standard treatment calibrated at 1.25 litres/min. One tank mix of $0.4 \mathrm{~g} /$ litre PTSA was used for all treatments to ensure uniformity of the active ingredient (dye).

The tractor throttle was set to deliver at a $6 \mathrm{~km} / \mathrm{h}$ speed and three down-and-back passes were made while spraying to ensure a sufficient capture of fluorescent material. Once spraying was complete, aluminium collectors were stowed in a pre-labelled plastic bag and pre-labelled Petri dishes were capped and placed in bags. All collectors were then placed in dark, cool storage to avoid any unexpected photo-degradation.

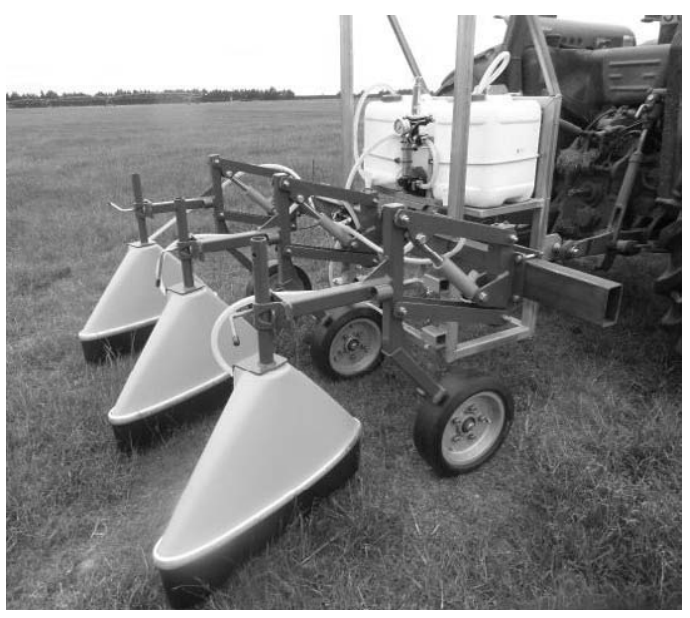

Figure 1 Sprayer setup with Varidome hoods.

Table 1 Meteorological data, presented as the average for each treatment.

\begin{tabular}{lccc}
\hline Treatment & Temperature $\left({ }^{\circ} \mathrm{C}\right)$ & Humidity $(\%)$ & Wind speed $(\mathrm{km} / \mathrm{h})$ \\
\hline Standard 110-03 & 13.1 & 64.7 & 11.9 \\
Hoods w/ DG 95-02 & 13.0 & 64.3 & 11.4 \\
DG 95-02 Alone & 13.0 & 64.5 & 12.7 \\
Hoods w/ DG 95-015 & 13.1 & 64.8 & 9.7 \\
DG 95-015 Alone & 13.1 & 65.0 & 12.6 \\
\hline
\end{tabular}


This whole process was repeated a total of three times for each nozzle/hood treatment.

Analysis consisted of dye extraction using $30 \mathrm{ml}$ of 10:90 isopropyl alcohol:deionised water solution. The solution was either distributed within each Petri dish or added to the same plastic bag in which the plates were stored. Samples were then swirled or shaken and allowed to rest for $10 \mathrm{~min}$ to further release fluorescent material. A $3 \mathrm{ml}$ subsample was then taken and read in a fluorometer (Turner Trilogy ${ }^{\circledR}$, Turner Designs, Sunnyvale, CA, USA), which was calibrated to parts-per-million (ppm) units before analysis commenced.

The data were collected and subjected to a Pearson's correlation to determine the similarities between collector types, and to do an analysis of variance (ANOVA) between treatments using SAS (9.3). Total collection means were then separated with Fisher's Protected LSD $(\mathrm{P}=0.05)$.

\section{RESULTS AND DISCUSSION}

The spray-hoods and low drift nozzles in this study significantly reduced spray drift compared to the 110-03 control, with total drift reduction between 95\% (DG 95-015 nozzles) and 99\% (DG 95-02 nozzles) when the spray-hoods were used, while the low drift nozzles alone reduced drift between 81\% (DG 95-015 nozzles) and 94\% (DG 95-02 nozzles) (Table 2). Although the use of low drift nozzles paired with spray-hoods showed a decrease of drift potential and no statistical differences were observed with or without the hoods, drift from the low drift nozzles alone were 1.4 to 17 times higher than with the hooded treatments. This was likely due to the increased number of fine particles produced by the Drift Guard nozzles compared to other low drift nozzles, such as air-induction types as discussed by Womac et al. (1997) and Ramsdale \& Messersmith (2001). This phenomenon was also observed in the farthest sampling distances $(\geq 25 \mathrm{~m}$ ) as more dye was collected for the DRT treatments than with the control, although no statistical differences were observed beyond $5 \mathrm{~m}$.

Hoods are typically meant to be utilised within the crop inter-rows. The crop itself provides further protection from drift. However, it is also essential that further loss of the applied solution is kept under control, particularly if it will have a negative effect to the primary cropping system. Previous research in the UK (Clayton 2014) reported that the Varidome brand hoods performed well for weed control when used in drilled oil seed rape and sugar beets with no crop injury. Further, the ability to spray non-selective herbicides (i.e. diquat, glyphosate, etc.) between crop rows can assist in the battle of pesticide resistance and where genetically modified crops (i.e. glyphosate resistant crops) are not available, such as in New Zealand. This is particularly important to New Zealand now that

Table 2 Concentration of PTSA fluorescent dye (ppm; mean for both collector types) relative to the standard 110-03 nozzle treatment for DG 95-015 and DG 95-02 nozzles, with or without spray hoods, measured from 0.25 to $100 \mathrm{~m}$ downwind of the spray path.

\begin{tabular}{|c|c|c|c|c|c|}
\hline \multirow{2}{*}{$\begin{array}{l}\text { Distance } \\
(\mathrm{m})\end{array}$} & \multirow{2}{*}{$\begin{array}{c}\text { Standard } \\
110-03\end{array}$} & \multicolumn{2}{|c|}{ DG 95-02 } & \multicolumn{2}{|c|}{ DG 95-015 } \\
\hline & & With hoods & Alone & With hoods & Alone \\
\hline 0.25 & $19,948 \mathrm{C}^{1}$ & $177 \mathrm{~A}$ & $1,108 \mathrm{~A}$ & $706 \mathrm{~A}$ & $3,201 \mathrm{C}$ \\
\hline 0.5 & 7,341 B & $42 \mathrm{~A}$ & $436 \mathrm{~A}$ & $356 \mathrm{~A}$ & $1,571 \mathrm{C}$ \\
\hline 1 & $3,114 \mathrm{~B}$ & $16 \mathrm{~A}$ & $251 \mathrm{~A}$ & $171 \mathrm{~A}$ & 786 B \\
\hline 2 & $1,108 \mathrm{~B}$ & $25 \mathrm{~A}$ & $125 \mathrm{~A}$ & $60 \mathrm{~A}$ & $311 \mathrm{AB}$ \\
\hline 5 & $129 \mathrm{AB}$ & $19 \mathrm{~A}$ & $22 \mathrm{~A}$ & $50 \mathrm{~A}$ & $73 \mathrm{~A}$ \\
\hline 10 & $21 \mathrm{~A}$ & $20 \mathrm{~A}$ & $16 \mathrm{~A}$ & $45 \mathrm{~A}$ & $22 \mathrm{~A}$ \\
\hline 25 & $11 \mathrm{~A}$ & $22 \mathrm{~A}$ & $17 \mathrm{~A}$ & $15 \mathrm{~A}$ & $26 \mathrm{~A}$ \\
\hline 50 & $11 \mathrm{~A}$ & $13 \mathrm{~A}$ & $19 \mathrm{~A}$ & $15 \mathrm{~A}$ & $10 \mathrm{~A}$ \\
\hline 100 & $8 \mathrm{~A}$ & $15 \mathrm{~A}$ & $37 \mathrm{~A}$ & $22 \mathrm{~A}$ & $12 \mathrm{~A}$ \\
\hline Mean & $3521 \mathrm{~A}$ & $39 \mathrm{~B}$ & $226 \mathrm{~B}$ & $160 \mathrm{~B}$ & $668 \mathrm{~B}$ \\
\hline
\end{tabular}

${ }^{1}$ Statistical difference based upon Fisher's Protected LSD; treatments with the same letters within a row are not statistically different $(\mathrm{P}=0.05)$. 
glyphosate-resistant Italian and perennial ryegrass have been discovered (Ghanizadeh et al. 2013)

Previous research on spray hoods, shields and shrouds has found reductions in overall drift from many designs, both fabricated in-house or commercially available (Fehringer \& Cavaletto 1990; Wolf et al. 1993; Ozkan et al. 1997; Sidahmed et al. 2004). The Varidome hoods used in the study were solid plastic and encased a single nozzle attached to a self-levelling frame, which is important in ensuring consistent results. However, Wolf et al. (1993) noted that this design does not allow the applicator to see the nozzle, which could allow a problem that might impede its proper function to go unnoticed.

Lastly, aluminium plates were shown to be a useful collector of driftable matter. Using Pearson's test for correlation, it was shown that the overall correlation between the two collector types was strong at a value of $0.81(\mathrm{P}<0.0001)$. There was no evidence that the two collectors significantly differed regardless of distance and driftable mass. Also, the use of PTSA for drift research is gaining popularity over other common dyes such as pyranine and rhodamine, but few data have been published to date. Hoffman et al. (2014) noted that the use of PTSA for drift research is highly reliable and recoverable with the use of a $10 \% \mathrm{v} / \mathrm{v}$ isopropyl alcohol for extraction on mylar cards as well as on the leaves of various plant species. The present study also demonstrated PTSA's reliability when used with Petri dishes and aluminium plates.

\section{ACKNOWLEDGEMENTS}

This research was funded by The Ministry for Business, Innovation and Employment, Contract LVLX0901 - "Protecting NZ's Environment from Pesticide Exposure". The authors would also like to thank Micron Group for providing Varidome equipment and Alasdair Noble at AgResearch for statistical support.

\section{REFERENCES}

Clayton JS 2014. The Varidome precision band sprayer for row crops. Aspects of Applied Biology 122: 55-62.
Dill GM, CaJacob CA, Padgette SR 2008. Glyphosate-resistant crops: adoption, use and future considerations. Pest Management Science 64(4): 326-331.

Fehringer RJ, Cavaletto R 1990. Spray drift reduction with shrouded boom sprayers. Proceeding of the 1990 International Meeting of the American Society of Agricultural Engineers, Columbus, Ohio, USA. Pp. 1-9.

Ghanizadeh H, Harrington KC, James TK, Woolley DJ 2013. Confirmation of glyphosate resistance in two species of ryegrass from New Zealand vineyards. New Zealand Plant Protection 66: 89-93.

Hanks JE, Beck JL 1998. Sensor-controlled hooded sprayer for row crops. Weed Technology 12(2): 308-314.

Hoffman WC, Frintz BK, Ledebuhr MA 2014. Evaluation of 1, 3, 6, 8-Pyrene tetra sulfonic acid tetra sodium salt (PTSA) as an agricultural spray tracer dye. Applied Engineering in Agriculture 30(1): 25-28.

Ozkan HE, Miralles A, Sinfort C, Zhu H, Fox RD 1997. Shields to reduce spray drift. Journal of Agricultural Engineering Research 67(4): 311-322.

Ramsdale BK, Messersmith CG 2001. Driftreducing nozzle effects on herbicide performance. Weed Technology 15(3): 453460.

Sidahmed MM, Awadalla HH, Haidar MA 2004. Symmetrical multi-foil shields for reducing spray drift. Biosystems Engineering 88(3): 305-312.

Wolf TM, Grover R, Wallace K, Shewchuk SR, Maybank J 1993. Effect of protective shields on drift and deposition characteristics of field sprayers. Canadian Journal of Plant Science 73(4): 1261-1273.

Womac AR, Goodwin JC, Hart WE 1997. Tip selection for precision application of herbicides. University of Tennessee Agricultural Experiment Station. http://trace. tennessee.edu/utk_agbulletin/430/ (accessed 1 April 2014). 